\title{
Bolstering and Restoring Feelings of Competence via the IKEA Effect
}

\section{Citation}

Mochon, Daniel, Michael I. Norton, and Dan Ariely. "Bolstering and Restoring Feelings of Competence via the IKEA Effect." International Journal of Research in Marketing 29, no. 4 (December 2012): 363-369.

\section{Published Version}

http://dx.doi.org/10.1016/j.ijresmar.2012.05.001

\section{Permanent link}

http://nrs.harvard.edu/urn-3:HUL.InstRepos:11320608

\section{Terms of Use}

This article was downloaded from Harvard University's DASH repository, and is made available under the terms and conditions applicable to Open Access Policy Articles, as set forth at http:// nrs.harvard.edu/urn-3:HUL.InstRepos:dash.current.terms-of-use\#OAP

\section{Share Your Story}

The Harvard community has made this article openly available.

Please share how this access benefits you. Submit a story.

Accessibility 
Bolstering and Restoring Feelings of Competence via the IKEA Effect

\author{
Daniel Mochon ${ }^{a^{*}}$ \\ Michael I. Norton ${ }^{\mathrm{b}}$ \\ Dan Ariely ${ }^{c}$
}

${ }^{a}$ Freeman School of Business, Tulane University, 7 McAlister Drive, New Orleans, LA, 70118

${ }^{b}$ Harvard Business School, Soldiers Field Road, Boston, MA, 02163

${ }^{c}$ Duke University, 1 Towerview Drive, Durham, NC, 27708

*Corresponding Author

Tel: +1-504-862-8067

Email: dmochon@tulane.edu 


\begin{abstract}
We examine the underlying process behind the IKEA effect - people's willingness to pay more for self-made products than for identical ones made by others - and the factors that influence both people's willingness to engage in self-assembly and the utility they derive from such activities. We propose that assembling products fulfills a core psychological need - consumers' desire to signal to themselves and others that they are competent - and that the feelings of competence associated with self-made products lead to the products' increased valuation. We demonstrate that the feelings of competence that arise from self-made products mediate their increased value (Experiment 1), that affirming consumers' sense of self decreases the value they derive from their creations (Experiment 2), and that threatening that sense of self increases consumers' propensity to make things themselves (Experiments 3A and 3B).
\end{abstract}




\section{Introduction}

A multitude of companies have emerged that allow consumers to create and design their own products, such as T-shirts, coffee mugs and ties. LEGO has a large and profitable online community where adult fans of LEGO can generate and submit their own designs. Local Motors even offers the unique experience of being involved in the assembly of one's own automobile. This trend is also prevalent on new media channels, where people seem more interested in creating and sharing their own amateurish videos than consuming professionally produced content. Consumers even enjoy repurposing products beyond their original designs; Ikeahackers.net provides how-to guides on reconfiguring standard IKEA products, such as bookshelves, for less-standard uses - like artsy hamster cages. In short, consumers are increasingly acting as co-creators of goods rather than as just passive recipients (Firat, Dholakia, \& Venkatesh, 1995; Prahalad \& Ramaswamy, 2000, 2002; Vargo \& Lusch, 2004). Why is cocreation of products so popular among consumers?

Functional fit is one of the most evident benefits of co-creation. By being involved in the production of a good, or by customizing it to one's taste, it is more likely to meet one's specific needs (Dellaert \& Stremersch, 2005; Franke, Keinz, \& Steger, 2009; Franke \& Piller, 2004;

Randall, Terwiesch, \& Ulrich, 2007; Schreier, 2006; Simonson, 2005). Additionally, co-creation likely results in products that no one else owns, and research has shown that customers get utility from having truly unique goods (Franke \& Schreier, 2008; Lynn \& Harris, 1997; Michel, Kreuzer, Kuhn, Stringfellow, \& Schumann, 2009). Finally, customers might derive utility from the fun involved in the design process itself (Csikszentmihalyi, 1990; Dahl \& Moreau, 2007; Dellaert \& Stremersch, 2005; Franke \& Schreier, 2010). 
While the above factors account for some of the benefits of co-creation, recent research has shown that consumers tend to overvalue their own creations even after controlling for these effects (Franke, Schreier, \& Kaiser, 2010; Norton, Mochon, \& Ariely, 2012). In one experiment, participants were willing to pay significantly more for an IKEA storage box they built than for an identical one built by someone else. This effect - labeled the "IKEA effect" - showed that people place more value on their own creations, even for mundane products that are not fun to build, unique, or customized (Norton et al., 2012). Why is it that customers value their own creations more highly than essentially identical products built by others? And what conditions both lead people to seek out the opportunity to create products and influence the utility people obtain from self-assembly?

We suggest that the attractiveness of self-created products is due in part to their role in fulfilling a deep identity-related desire of consumers: their desire to signal a competent identity to themselves and others. Self-assembly of products fulfills this need: by building things themselves, people are both controlling and shaping their environments - proving their own competence - and displaying those creations demonstrates that competence to others. Indeed, Dahl and Moreau (2007) found that "feelings of competence" was the most commonly mentioned motivation for engaging in creative tasks. We therefore propose that the competence consumers associate with self-made products drives the premiums they attach to those creations. Consequently, consumers will be relatively more attracted to opportunities to self-assemble when their feelings of competence have been threatened, and they will derive relatively less utility from self-assembly when their sense of competence has already been affirmed.

\subsection{Signaling Identities to the Self and Others}


People learn about their preferences and their identity from their own actions (Ariely \& Norton, 2008; Bem, 1972); in turn, people prefer to act consistently with those identities, since behavior that confirms identities creates utility (Akerlof \& Kranton, 2000; LeBoeuf, Shafir, \& Bayuk, 2010). Recent research has demonstrated that people not only behave in accordance with existing identities, but also actively use their behavior to send "evidence" to themselves that they possess desired identities (Benabou \& Tirole, 2011; Bodner \& Prelec, 2003; Gneezy, Imas, Nelson, Brown, \& Norton, 2012).

What important self-signal of identity does creating products send? A large body of literature demonstrates a fundamental human need for effectance - an ability to successfully produce desired outcomes in one's environment - and one means by which people accomplish this goal is by affecting and controlling objects and possessions (Bandura, 1977; Belk, 1988; Furby, 1991; White, 1959). As such, self-created products can be used to signal a competent identity to the self. In addition, completed products can signal a competent identity to others. Indeed, consumers actively use products to signal their identities to others (Belk, 1988; Berger \& Heath, 2007; Wernerfelt, 1990) and have been shown to use certain products, such as featurerich electronic products, as a way to signal their competence (Thompson \& Norton, 2011). We therefore predict that the IKEA effect is driven by the feelings of competence associated with self-creations. Self-made products act as signals competence for the self and others, leading to improved evaluations of these products, and higher willingness to pay in order to keep them. Indeed, losing one's possessions can deprive people of the sense of self attached to those objects (Belk, 1988).

We provide initial support for our account by examining whether feelings of competence associated with self-assembled products, which we operationalize as their feelings of pride about 
their creations, mediate the IKEA effect. Pride is closely linked to experiences of success and failure across a wide domain of tasks involving self-efficacy and competence - from taking boring math tests to winning sports events - and is strongly linked to people's self-evaluations of their identity (Buss, 2001; Lazarus, 1991; Tracy \& Robins, 2004a; Weiner, 1985, 1986; Weiner, Russell, \& Lerman, 1979). Research shows that participants list words such as "accomplished" when asked to describe feeling proud (Tracy \& Robins, 2007), and pride is associated with dominance among mammals (Tracy \& Robins, 2004b) - offering further evidence that pride is closely linked to feelings of success and competence. A similar construct - "feelings of accomplishment" - mediates the impact of successfully designing hedonic products (such as Tshirts) on consumers' increased willingness to pay (Franke et al., 2010). We therefore predicted that feelings of competence - as assessed by pride - would similarly drive consumers' increased willingness to pay for their self-assembled products. In contrast with this previous research, however - and in line with research suggesting that pride is associated with successful completion of both boring tests and exciting competitions - we predicted that pride would drive increased willingness to pay even when participant assembled mundane products, like IKEA boxes.

In addition to measuring the feelings of competence associated with self-assembled products, we test our account by directly manipulating participants' need to signal competence, and examining the consequences of these manipulations on the value derived from self-creation. Self-affirmation theory argues that people strive to keep a positive view of the self (Aronson, Cohen, \& Nail, 1999; Sherman \& Cohen, 2006), with research suggesting that people utilize a "fluid compensation" procedure, whereby affirming one important value to the self can temporarily reduce the weight placed on a different value (Steele, 1988). Therefore, if the IKEA 
effect is driven by the ability of self-made products to signal a valued identity, this effect should be reduced or eliminated if participants are first allowed to affirm the self. Conversely, threatening people's sense of competence should increase the value they derive from selfcreation and increase their propensity to engage in such activities. Indeed, affirming the self has been shown to reduce the likelihood of choosing products that signal important components of the self, while threatening the self has been shown to have the opposite effect (e.g. Gao, Wheeler, \& Shiv, 2009; Townsend \& Sood, 2012).

\subsection{Overview of the Studies}

We present a series of studies where we both manipulate and measure the feelings of competence associated with self-assembled products. In Experiment 1, we examine whether feelings of pride associated with one's creation mediate the effect of self-assembly on willingness to pay. In addition, we rule out a mood based explanation for the effect. In Experiment 2, we provide additional evidence for our account by not only measuring feelings of competence associated with self-assembled products, but also by manipulating the need to signal competence. If our account is correct, participants who have affirmed their identity and who do not require further boosts to their sense of competence will receive less benefit from self-made products and consequently not show the IKEA effect.

Finally, in Experiments 3A and 3B, we use a different design to demonstrate the importance of feelings of competence in self-assembly and co-creation. We first shake participants' sense of competence in one domain and then measure whether this increases their

propensity to engage in self-assembly. If people use self-made products to signal competence, 
then they might be more willing to engage in co-creation when their feelings of competence have been threatened. Taken together, these experiments provide converging evidence for the notion that people value self-made products because of their ability to signal competence to themselves and others.

\section{Experiment 1}

In Experiment 1, we examined whether the increased value of self-made products is driven by the competence associated with them. In this study, participants were assigned to build a product or were presented with a pre-built one that they were asked to examine. We then elicited their willingness to pay for the product, the feelings of competence associated with the product, and their overall mood. We predicted that, replicating prior work (Franke et al., 2010; Norton et al., 2012), participants would be willing to pay more for the same product when they created it. Importantly, we predicted that this effect would be mediated by the feelings of competence - pride - associated with the product.

In this study we also distinguished our competence-based account from a mood-based account (Schwarz \& Clore, 1983), in which positive mood associated with creation might lead directly to increased willingness to pay. In line with prior work on task success and mood (e.g. Weiner et al., 1979), we predicted that successful self-assembly would improve consumers' mood; however, we predicted that mood alone would not mediate the effect of self-assembly on willingness to pay, but rather that pride associated with the product would act as a mediator both for increased willingness to pay and elevated mood.

\subsection{Method}


Participants $(N=79 ; 33$ male) were paid $\$ 5$ to complete the experiment. We excluded three participants for failing to complete all of the questions and one extreme outlier (more than 3 SDs from the mean on the WTP measure).

We randomly assigned some participants - our builders - to assemble a LEGO car. These participants were given the pieces for the car with the assembly instructions that come with the product. The other participants - our non-builders - were given the car already assembled and asked to examine it. We next solicited their reservation price by asking them to bid on their creation. We told them that we would draw a random price (from an unknown distribution); if their number was equal to or above that price, they would pay us that amount and take their LEGO car home, while if their bid was below the price, they would not purchase their LEGO car. This technique is an incentive compatible value elicitation method, a variant of the BeckerDeGroot-Marschak (1964) procedure. Note that there was no opportunity for customizing this product, so participants in both conditions were effectively bidding on the same product.

Participants then answered two questions designed to measure the feelings of competence associated with the product they created. Specifically, participants were asked to rate on 7-point scales the extent to which they felt proud of the product they created (Franke et al., 2010) and the extent to which they planned to show off their product to other people $(r=.33, p<.01)$. We averaged these two measures to create a composite measure of competence associated with one's product. Finally, participants completed the Positive and Negative Affect Schedule (PANAS; Watson, Clark, \& Tellegen, 1988), indicating the extent to which they felt a variety of positive (e.g., happy) and negative (e.g., upset) affective states on 5-point scales (1: not at all, 5: extremely). We averaged items from the PANAS to form separate indices of positive and negative affect (Cacioppo, Gardner, \& Berntson, 1999). 


\subsection{Results and Discussion}

We found that the builders bid significantly more for their cars $(M=\$ 1.20, S D=1.35)$ than the non-builders $(M=\$ 0.57, S D=.76 ; t(73)=2.44, p<.05)$. While both groups were given the chance to buy the same product, those who perceived themselves to be the creators of the product imbued it with significantly more value - despite the fact that the non-builders could easily have disassembled their set and reassembled it.

We next examined the competence measure to test the underlying mechanism of the IKEA effect. As predicted, feelings of competence were higher for builders $(M=4.39, S D=$ 1.48) than non-builders $(M=2.81, S D=1.34 ; t(73)=4.85, p<.001$; Table 1$)$. More importantly, competence was significantly related to participants' WTP $(r=.36, p<.01)$. We therefore examined whether competence mediated the effect of self-assembly on willingness to pay (Baron \& Kenny, 1986). While condition was a significant predictor of willingness to pay on its own $(B$ $=.62, S E=.26 ; t(73)=2.44, p<.05)$, this effect became non-significant when competence was entered into the equation $(B=.29, S E=.28 ; t(72)=1.02, p=.30)$, while the effect of the mediator remained significant $(B=.21, S E=.09 ; t(72)=2.35, p<.05)$. Thus, the feelings of competence associated with the product significantly mediated the effect of condition on willingness to pay (Sobel's $Z=2.08, p<.05$ ). These results provide initial support for our claim that people are willing to pay more for products they create because of the feelings of competence that arise from successful self-assembly. 
We further predicted that the feelings of competence associated with creation would lead to better mood for those in the build condition, but that mood itself would not drive the increased willingness to pay for self-assembled products. The two groups did not differ in negative affect $(t$ $<1)$, however, builders reported more positive affect $(M=2.80, S D=.73)$ than non-builders $(M$

$=2.30, S D=.91 ; t(73)=2.61, p=.01)$. Moreover, the competence scale was significantly related to participants' positive affect $(r=.36, p<.001)$, and, as with WTP, feelings of competence significantly mediated the effect of condition on positive affect (Sobel's $\mathrm{Z}=2.05, p<.05$ ). Thus, feeling competent not only affected participants' liking of their self-assembled products, but also participants' overall happiness. Importantly for our account, however, the effect of experimental condition on WTP was not driven by participants' mood. When both variables were entered into the regression as potential mediators (Preacher \& Hayes, 2008), competence was a significant mediator (Sobel's $\mathrm{Z}=2.01, p<.05$ ), but positive mood was not (Sobel's $\mathrm{Z}=.39, p=.70$ ), suggesting that competence plays the critical role, as we predicted.

\section{Experiment 2}

The first experiment provided initial support for our theory that self-made products are valued more because of their influence on feelings of competence. In Experiment 2, we tested our account by not only measuring (as in the previous experiment), but also directly manipulating participants' need to feel competent, via a self-affirmation manipulation. Selfaffirmation theory suggests that people possess a "fluid compensation" procedure, whereby 
affirming one important value reduces the need to affirm another one (Steele, 1988); if the IKEA effect is driven by the impact of self-assembly on feelings of competence, the effect should be reduced or eliminated if participants are first allowed to affirm their sense of self in another way. Unlike existing research in which consumers used more hedonic products to restore the self (e.g., Gao et al., 2009; Townsend \& Sood, 2012), in this study we used a mundane product - IKEA storage boxes - to show that even boring products can be used to increase people's feelings of competence, expanding the range of products that can be used to affirm one's identity.

\subsection{Method}

Participants $(N=135 ; 75$ male) completed this study to fulfill a requirement for an undergraduate introductory class. We excluded eleven participants who did not complete the self-affirmation task by failing to rank their values correctly and five participants who did not complete all of our dependent measures.

Participants were randomly assigned to one of four conditions of a 2 self-affirmation condition (no affirmation vs. self-affirmation) x 2 build condition (pre-built vs. build) betweensubjects design. Participants in this experiment were randomized by experimental session to ensure they could not see participants in the other conditions.

Following the procedure used by Sherman, Nelson and Steele (2000), participants were first presented with a list of 11 values and ranked them from most important to least important to them. On the next page, participants were asked to write an essay about why a particular value was important to them and to describe a time when it had been particularly important.

Participants in the self-affirmation condition were asked to write about the value they ranked as 
most important; participants in the no affirmation condition were asked to write about their ninth-ranked value.

Following the self-affirmation manipulation, participants were presented with an IKEA Kassett storage box. Those in the pre-built condition were presented with a box that was already built and were asked to examine it. Those in the build condition were given the parts necessary to assemble the box, as well as the instructions from IKEA to assemble it, and assembled the box.

Participants were then asked to state the maximum they would be willing to pay for this box on a scale ranging from $\$ 0$ to $\$ 2$ in 10 cent increments; we implemented a BDM procedure as in the previous study. All participants were paid $\$ 2$ for completing this task to ensure they all had money to spend on the box; we used a square root transformation to correct for the skewness of the WTP distribution. Finally, participants completed the competence measures from Experiment $1(r=.47, p<.001)$.

\subsection{Results and Discussion}

We analyzed participants' willingness to pay using a 2 self-affirmation condition (noaffirmation vs. self-affirmation) x 2 build condition (pre-built vs. build) between-subjects ANOVA. This analysis did not reveal a significant main effect of the self-affirmation manipulation $(F(1,115)=.44, p=.51)$ or a significant main effect of build condition $(F(1,115)=$ $1.06, p=.31)$. Most importantly for our account, we observed the predicted interaction between these two variables $(F(1,115)=3.90, p=.05$; Figure 1$)$. In the no-affirmation condition, we replicated the standard IKEA effect: builders $(M=\$ 0.72, S D=.45)$ were willing to pay significantly more than non-builders $(M=\$ 0.46, S D=.50 ; t(52)=1.99, p=.05)$. This effect was 
eliminated for participants in the self-affirmation condition, where there was no significant difference between builders $(M=\$ 0.49, S D=.46)$ and non-builders $(M=\$ 0.58, S D=.46 ; t(63)$ $=.71, p=.48)$. Thus, providing participants with an opportunity to affirm the self eliminated the IKEA effect.

Insert figure 1 about here

We next conducted an ANOVA to examine how the experimental conditions affected participants' ratings on the competence scale. This analysis showed no significant main effect of self-affirmation $(F(1,115)=1.0, p=.30)$ but a significant main effect of build condition $(F(1,115)=19.8, p<.001)$. Replicating the previous experiment, builders reported higher feelings of competence $(M=2.95, S D=1.50)$ than non-builders $(M=1.94, S D=1.13)$. Importantly, this main effect was qualified by the predicted significant interaction $(F(1,115)=$ $5.8, p<.05)$. As before, participants in the no-affirmation condition reported higher feelings of competence when they built the box $(M=3.39, S D=1.62)$ than when they received it preassembled $(M=1.76, S D=1.01 ; t(52)=4.55, p<.001)$. However, participants who were first given a chance to self-affirm their values showed no such effect $\left(M_{\text {Build }}=2.57\right.$, vs. $M_{\text {Pre-Built }}=$ $2.09 ; t(63)=1.53, p=.13)$.

We therefore tested a model of moderated mediation to examine whether the indirect effect of competence on WTP depended on self-affirmation (Preacher, Rucker, \& Hayes, 2007). Replicating the above ANOVA (see Table 2), we found that there was a significant main effect of build condition on the competence mediator $(B=1.63, p<.001)$, which was qualified by a significant interaction between the build and self-affirmation conditions $(B=-1.15, p<.05)$. 
Moreover, when the competence mediator was included in the model predicting WTP, the effect of the mediator was significant $(B=.12, p<.001)$, while the main effect of build condition $(B=$ $.07, p=.59)$ and its interaction with self-affirmation $(B=-.21, p=.22)$ were no longer significant. These results suggest that, as in the previous study, competence acted as a mediator of the effect of building on WTP but that this effect was moderated by the self-affirmation manipulation. Indeed, the analyses revealed a significant conditional indirect effect of the competence mediator in the no-affirmation condition $(B=.19, S E=.07 ; Z=2.80, p<.01)$, and a non-significant conditional indirect effect of the mediator in the self-affirmation condition $(B=$ $.06, S E=.04 ; Z=1.34, p=.18)$.

Insert table 2 about here

\section{Experiment 3A}

The previous experiments demonstrated that the IKEA effect is mediated by feelings of competence associated with one's own creations. In Experiments 3A and 3B, we used a different paradigm to provide further support for our account. We examined whether manipulating feelings of competence directly could affect consumers' propensity to engage in self-assembly. Since consumers value self-made products in part because they can be used to bolster feelings of competence, then they may be more willing to engage in such tasks when their sense of competence has been shaken (Gao et al., 2009). In both studies, we gave consumers the choice to assemble products or not (see Moreau \& Herd, 2010) and examined whether those whose confidence had been shaken were more likely to choose products that required assembly. 


\subsection{Method}

Participants $(N=75 ; 42$ male $)$ completed an online survey and were randomly assigned to one of two conditions, which manipulated their sense of competence. Participants in the highcompetence condition were presented with four easy math problems (e.g., How likely is it that a fair coin that is tossed once will come up heads?). Participants in the low-competence condition were presented with four very difficult math problems (e.g., You have 4 coins. Three of the coins are normal, but one of them is heads on both sides. You pick a coin at random without looking. The coin you pick has heads on one side. What are the odds that if you flip the coin over, the other side will be tails?). All questions were presented with four potential answers, and participants were told that they could skip questions if they did not know the answer. Following the competence manipulation, participants were shown the picture of a bookcase from IKEA, and were asked: "Imagine that you bought the above bookcase from IKEA. Would you prefer that it came pre-assembled, or would you prefer to assemble it yourself?"

\subsection{Results and Discussion}

We first examined whether our competence manipulation was successful. Participants in the high-competence condition solved $92 \%$ of the questions correctly, while participants in the low-competence condition solved just $22 \%$ of the questions correctly - no better than chance.

We next examined whether this manipulation affected participants' propensity to assemble their own products. As predicted by our account, shaking people's feelings of 
competence increased the likelihood that they would want to assemble their own bookcase. While only $33 \%$ of participants in the high-competence condition said they would prefer to assemble the bookcase themselves, $58 \%$ of participants in the low-competence condition indicated they would prefer to $\left(\chi_{(1)}^{2}=4.72, p<.05\right)$. These results further highlight the critical role that competence plays in the IKEA effect. Not only did feelings of competence act as a mediator of the effect, but threatening consumers' confidence affected their propensity to engage in self-assembly. These results also expand research on self-affirmation in consumer behavior (e.g., Gao et al., 2009) by demonstrating that consumers can restore their shaken sense of self even with extremely mundane activities - such as building a bookcase.

Insert figure 2 about here

\section{Experiment 3B}

In a follow-up experiment, we examined whether we could replicate the effect on choice we observed in experiment $3 \mathrm{~A}$ using a decision that more closely matches one that consumers would face in everyday life.

\subsection{Method}

Participants $(N=41 ; 24$ male) completed a short online survey which threatened their feelings of competence and then presented them with a consumer choice. Participants were first presented with either one easy or one difficult math problem drawn from those used in the 
previous experiment (we used the ones given as examples above). Following this manipulation, they were shown two tables and were asked which they would prefer. One of the tables was from Target, and participants were told that the table would arrive pre-assembled. The other table was from IKEA, and participants were told that they would have to assemble this table. The image of the table corresponding to the IKEA vs. Target table was counterbalanced to control for any preferences for one of the two tables.

\subsection{Results and Discussion}

As in the previous study, the competence manipulation was successful. $96 \%$ of participants in the high-competence condition got the math question correct, while $26 \%$ of those in the low-competence condition did so (doing no better than chance). More importantly, participants in the low-competence condition were significantly more likely to choose the IKEA table $(74 \%)$ - which required some assembly - than those in the high-competence condition $\left(27 \% ; \chi_{(1)}^{2}=8.79, p<.01\right)$. These results further support our claim that feelings of competence play a critical role in the value that people derive from their own creations.

These results also have important practical implications. In spite of benefits of cocreation for firms (consumers' willingness to pay more for products they build, lower costs, etc.) and for consumers (increased feelings of competence after successfully assembling products), consumers are often reluctant to participate in such activities. When we asked a different group $(N=51)$ : "In general, what would you be willing to pay more for, products that you buy already assembled, or products that you buy with some assembly required," a full $92 \%$ said they would pay more for preassembled products, $\left(\chi_{(1)}^{2}=36.26, p<.001\right)$. The results from the previous two 
studies suggest that involvement in co-creation may be increased by appealing to consumers' sense of competence and their need to signal it to others.

Taken together, Experiments 2, 3A, and 3B demonstrated a critical role for feelings of competence - the mediator that we suggested underlies the IKEA effect - in both consumers' propensity to engage in self-assembly (with threats to competence increasing their desire to build products themselves) and the benefits they reap from self-assembly (with affirmation attenuating the positive effects of building).

\section{General Discussion}

Prior research has demonstrated that people are willing to pay more for goods they created than for objectively identical goods created by someone else (Franke et al., 2010; Norton et al., 2012). We proposed that this increase in valuation occurs because of the feelings of competence associated with self-created products. In Experiment 1, we demonstrated how the competence associated with self-created products mediates the increase in value for such products relative to products created by others. In Experiments 2, 3A, and 3B, we manipulated consumers' need to signal competence to further demonstrate the critical role of this construct in the IKEA effect. Affirming consumers' sense of self caused self-assembly of products to be less rewarding, while threatening consumers' feelings of competence led them to seek out opportunities to build products in an effort to restore their shaken sense of competence. Taken together, the experiments offer evidence of the crucial role that competence plays - as both mediator and moderator - in creating consumer interest in building products and in causing those efforts to feel rewarding. These results also demonstrate that even some of the most mundane 
activities that consumers can engage in - such as assembling a storage box - can have implications for consumers' sense of self, expanding prior research demonstrating how products can be used to affirm the self (e.g., Gao et al., 2009; Townsend \& Sood, 2012).

\subsection{Signaling to the Self vs. Others}

Our measure of competence included one item about personal feelings of pride and one item about people's desire to show off their creations to others. Though the two constructs were correlated in each experiment, the relative contribution of these two kinds of competence wanting to feel proud about one's successful creations and wanting to show those creations off to others - will likely vary by context. One important factor determining which of the two is stronger is likely the type of product created. The products used in the current paper are relatively less likely to be displayed to others than products that are by their nature explicitly designed for showing off to others, such as clothing. Indeed, when people design products meant specifically for display - such as T-shirts and watches - the prospect of showing these off to others strongly contributes to their value (Franke et al., 2010). Another important factor is likely the salience of displaying one's creation to others. During the current experiments, participants were not given such an opportunity. However, given that the mere presence of others can increase people's concerns about the impressions they are making (Puntoni \& Tavassoli, 2007), it is possible that simply making the social context more salient would increase the relative impact of the desire to show off on the magnitude of the IKEA effect. Finally, the relative strength of these two factors also likely depends on the intended recipient of the created good (Moreau, Bonney, \& Herd, 2011). Much of the self-made content created for new media 
channels (such as YouTube videos) is made specifically for display to others; in these cases, is it likely that the utility associated with one's own creations is heavily dependent on their ability to signal one's competence to others. Future research is needed to examine the relative contributions of the two kinds of competence signals in understanding when and how people come to value their own creations.

\subsection{Co-creation and Customer Satisfaction}

These results have implications both for firms seeking to maximize customer satisfaction, and for individuals managing their life satisfaction. For firms, we note that while our results demonstrate that involving consumers in creation can lead to higher WTP, the effect we documented here is a retrospective phenomenon: having successfully built products, participants then valued the product of their labor more highly. Shaking consumers' sense of competence in Experiment 3 did increase consumers' desire to engage in co-creation, but absent that inducement, they were very unlikely to do so. Moreover, involving consumers in co-creation does not come without its risks: while consumers may attribute successful co-creation experiences to their own efforts, they may attribute co-creation failures to the firm, negatively impacting firm perceptions (Bendapudi \& Leone, 2003). Future research should examine the best way to encourage customers to co-create.

For individuals, our results from Experiment 1 demonstrating that self-assembly leads to increases in positive affect suggest that they may be leaving utility on the table by generally choosing to relax instead of engage in labor. A large body of research has pointed to the centrality of labor to people's well-being (Blustein, 2008), with the feeling of productivity 
serving as an important goal for many people (Hsee, Yang, \& Wang, 2010; Keinan \& Kivetz, 2011). For example, being deprived of labor - in the form of unemployment - has lasting psychological consequences; even when people obtain employment, the adverse impact of past job loss on well-being remains (Feather, 1990; Lucas, Clark, Georgellis, \& Diener, 2004). This perspective dovetails with other research suggesting that effortful activities - such as exercising (Mochon, Norton, \& Ariely, 2008), making time to behave prosocially toward others (Dunn, Aknin, \& Norton, 2008), and acquiring life experiences (Van Boven, 2005; Van Boven \& Gilovich, 2003) - can lead to lasting changes in people's well-being (Lyubomirsky, Sheldon, \& Schkade, 2005). As a result, encouraging people to engage in labor that they might be inclined to avoid may lead to increased life satisfaction. Future research is needed to explore this possibility. Finally, the overvaluation that occurs as a result of the IKEA effect has implications for organizations more broadly, as a contributor to two key organizational pitfalls: sunk cost effects (Arkes \& Blumer, 1985; Biyalogorsky, Boulding, \& Staelin, 2006; Staw, 1981), which can cause managers to continue to devote resources to failing projects in which they have previously invested (Biyalogorsky et al., 2006), and the "not invented here" syndrome, in which managers refuse to use perfectly good ideas developed elsewhere in favor of their - sometimes inferior internally-developed ideas. Our results suggest that when managers persist in pursuing failed projects and concepts, they may do so because they truly come to believe their ideas are more valuable - not pursuing them would be leaving money on the table and using a competitor's ideas would simply be choosing an inferior option. Not surprisingly, highly innovative projects are especially likely to generate over-commitment from managers (Schmidt \& Calantone, 1998). While markets may sometimes correct these erroneous overvaluations, the IKEA effect may be 
Competence and the IKEA Effect 23

resistant to any intervention, suggesting that the "not invented here" syndrome may be here to stay. 


\section{References}

Akerlof, G. A., \& Kranton, R. E. (2000). Economics and identity. The Quarterly Journal of Economics, 115, 715-753.

Ariely, D., \& Norton, M. I. (2008). How actions create -- not just reveal -- preferences. TRENDS in Cognitive Sciences, 12(1), 13-16.

Arkes, H. R., \& Blumer, C. (1985). The psychology of sunk cost. Organizational Behavior and Human Decision Processes, 35(1), 124-140.

Aronson, J., Cohen, G., \& Nail, P. R. (1999). Self-affirmation theory: an update and appraisal. In E. Harmon-Jones \& J. Mills (Eds.), Cognitive dissonance: Progress on a pivotal theory in social psychology (pp. 127-147). Washington, DC: American Psychological Association.

Bandura, A. (1977). Self-efficacy: Toward a unifying theory of behavioral change. Psychological Review, 84(2), 191-215.

Baron, R. M., \& Kenny, D. A. (1986). The moderator-mediator variable distinction in social psychological research: Conceptual, strategic, and statistical considerations. Journal of Personality and Social Psychology, 51(6), 1173-1182.

Becker, G. M., DeGroot, M. H., \& Marschak, J. (1964). Measuring utility by a single-response sequential method. Behavioral Science, IX, 226-232.

Belk, R. W. (1988). Possessions and the extended self. Journal of Consumer Research, 15(September), 139-168. 
Bem, D. J. (1972). Self-perception theory. In L. Berkowitz (Ed.), Advances in Experimental Social Psychology (Vol. 6, pp. 1-63). New York: Academic Press.

Benabou, R., \& Tirole, J. (2011). Identity, morals and taboos: Beliefs as assets. The Quarterly Journal of Economics, 126(2), 805-855.

Bendapudi, N., \& Leone, R. P. (2003). Psychological implications of costumer participation in co-production. Journal of Marketing, 67(January), 14-28.

Berger, J., \& Heath, C. (2007). Where consumers diverge from others: identity signaling and product domains. Journal of Consumer Research, 34(2), 121-134.

Biyalogorsky, E., Boulding, W., \& Staelin, R. (2006). Stuck in the past: Why managers persist with new product failures. Journal of Marketing, 70(April), 108-121.

Blustein, D. L. (2008). The role of work in psychological health and well-being: A conceptual, historical, and public policy perspective. American Psychologist, 63(4), 228-240.

Bodner, R., \& Prelec, D. (2003). The diagnostic value of actions in a self-signaling model. In I. Brocas \& J. Carillo (Eds.), The Psychology of Economic Decisions (Vol. 1). Oxford: Oxford University Press.

Buss, D. M. (2001). Human nature and culture: An evolutionary psychological perspective. Journal of Personality, 69(6), 955-978.

Cacioppo, J. T., Gardner, W. L., \& Berntson, G. G. (1999). The affect system has parallel and integrative processing components: Form follow function. Journal of Personality and Social Psychology, 76(5), 839-855.

Csikszentmihalyi, M. (1990). Flow: The Psychology of Optimal Experience. New York: Harper and Row. 
Dahl, D. W., \& Moreau, P. (2007). Thinking inside the box: Why consumers enjoy constrained creative experiences. Journal of Marketing Research, 44(3), 357-369.

Dellaert, B. G. C., \& Stremersch, S. (2005). Marketing mass-customized products: Striking a balance between utility and complexity. Journal of Marketing Research, 42, 219-227.

Dunn, E. W., Aknin, L. B., \& Norton, M. I. (2008). Spending money on others promotes happiness. Science, 319, 1687-1688.

Feather, N. T. (1990). The Psychological Impact of Unemployment. New York: Springer-Verlag.

Firat, A. F., Dholakia, N., \& Venkatesh, A. (1995). Marketing in a postmodern world. European Journal of Marketing, 29(1), 40-56.

Franke, N., Keinz, P., \& Steger, C. (2009). Testing the value of customization: When do customers really prefer products tailored to their preferences? Journal of Marketing, 73(5), 103-121.

Franke, N., \& Piller, F. (2004). Value creation by toolkits for user innovation and design: The case of the watch market. The Journal of Product Innovation Management, 21, 401-415.

Franke, N., \& Schreier, M. (2008). Product uniqueness as a driver of customer utility in mass customization. Marketing Letters, 19, 93-107.

Franke, N., \& Schreier, M. (2010). Why customers value self-designed products: The importance of process effort and enjoyment. Journal of Product Innovation Management, 27, 10201031.

Franke, N., Schreier, M., \& Kaiser, U. (2010). The “I Designed It Myself” Effect in Mass Customization. Management Science, 56(1), 125-140. 
Furby, L. (1991). Understanding the psychology of possession and ownership: A personal memoir and an appraisal of our progress. Journal of Social Behavior \& Personality, 66, 457-463.

Gao, L., Wheeler, S. C., \& Shiv, B. (2009). The "shaken self": Product choices as a means of restoring self-view confidence. Journal of Consumer Research, 36(June), 29-38.

Gneezy, A., Imas, A., Nelson, L. D., Brown, A., \& Norton, M. I. (2012). Paying to be nice: Consistency and costly prosocial behavior. Management Science, 58, 179-187.

Hsee, C. K., Yang, A. X., \& Wang, L. (2010). Idleness aversion and the need for justified busyness. Psychological Science, 21, 926-930.

Keinan, A., \& Kivetz, R. (2011). Productivity orientation and the consumption of collectable experiences. Journal of Consumer Research, 37(6), 935-950.

Lazarus, R. S. (1991). Progress on a cognitive-motivational-relational theory of emotion. American Psychologist, 46(8), 819-834.

LeBoeuf, R. A., Shafir, E., \& Bayuk, J. B. (2010). The conflicting choices of alternating selves. Organizational Behavior and Human Decision Processes, 111(1), 48-61.

Lucas, R. E., Clark, A. E., Georgellis, Y., \& Diener, E. (2004). Unemployment alters the set point for life satisfaction. Psychological Science, 15(1), 8-13.

Lynn, M., \& Harris, J. (1997). The desire for unique consumer products: A new individual differences scale. Psychology \& Marketing, 14(6), 601-616.

Lyubomirsky, S., Sheldon, K. M., \& Schkade, D. A. (2005). Pursuing happiness: The architecture of sustainable change. Review of General Psychology, 9(2), 111-131. 
Michel, S., Kreuzer, M., Kuhn, R., Stringfellow, A., \& Schumann, J. H. (2009). Masscustomized products: are they bought for uniqueness or to overcome problems with standard products? Journal of Customer Behavior, 8(4), 307-327.

Mochon, D., Norton, M. I., \& Ariely, D. (2008). Getting off the hedonic treadmill, one step at a time: The impact of regular religious practice and exercise on well-being. Journal of Economic Psychology, 29(5), 632-642.

Moreau, C. P., Bonney, L., \& Herd, K. B. (2011). It's the thought (and the effort) that counts: How customizing for others differs from customizing for oneself. Journal of Marketing, 75(September), 120-133.

Moreau, C. P., \& Herd, K. B. (2010). To each his own? How comparisons with others influence consumers' evaluations of their self-designed products. Journal of Consumer Research, 36(February), 806-819.

Norton, M. I., Mochon, D., \& Ariely, D. (2012). The IKEA effect: When labor leads to love. Journal of Consumer Psychology.

Prahalad, C. K., \& Ramaswamy, V. (2000). Co-opting customer competence. Harvard Business Review, 78(January), 79-87.

Prahalad, C. K., \& Ramaswamy, V. (2002). The co-creation connection. Strategy and Business, 27(2), 50-61.

Preacher, K. J., \& Hayes, A. F. (2008). Asymptotic and resampling strategies for assessing and comparing indirect effects in multiple mediator models. Behavior Research Methods, 40(3), 879-891. 
Preacher, K. J., Rucker, D. D., \& Hayes, A. F. (2007). Addressing moderated mediation hypotheses: Theory, methods, and prescriptions. Multivariate Behavioral Research, $42(1), 185-227$.

Puntoni, S., \& Tavassoli, N. T. (2007). Social context and advertising memory. Journal of Marketing Research, 44(May), 284-296.

Randall, T., Terwiesch, C., \& Ulrich, K. T. (2007). User design of customized products. Marketing Science, 26(2), 268-280.

Schmidt, J. B., \& Calantone, R. J. (1998). Are Really New Product Development Projects Harder to Shut Down? Journal of Product Innovation Management, 15(2), 111-123.

Schreier, M. (2006). The value increment of mass-customized products: an empirical assessment. Journal of Consumer Behaviour, 5, 317-327.

Schwarz, N., \& Clore, G. L. (1983). Mood, misattribution, and judgments of well-being: Informative and directive function of affective states. Journal of Personality and Social Psychology, 45(3), 513-523.

Sherman, D. K., \& Cohen, G. L. (2006). The psychology of self-defense: Self affirmation theory. In M. P. Zanna (Ed.), Advances in Experimental Social Psychology (Vol. 38, pp. 183242). San Diego: Academic Press.

Sherman, D. K., Nelson, L. D., \& Steele, C. M. (2000). Do messages about health risks threaten the self? Increasing the acceptance of threatening health messages via self-affirmation. Personality and Social Psychology Bulletin, 26(9), 1046-1058.

Simonson, I. (2005). Determinants of customers' responses to customized offers: Conceptual framework and research propositions. Journal of Marketing, 69(January), 32-45. 
Staw, B. M. (1981). The escalation of commitment to a course of action. Academy of Management Review, 6(4), 577-587.

Steele, C. M. (1988). The psychology of self-affirmation: Sustaining the integrity of the self. In L. Berkowitz (Ed.), Advances in experimental social psychology (Vol. 21, pp. 261-302). New York: Academic Press.

Thompson, D. V., \& Norton, M. I. (2011). The social utility of feature creep. Journal of Marketing Research, 48(June), 555-565.

Townsend, C., \& Sood, S. (2012). Self-affirmation through the choice of highly aesthetic products. Journal of Consumer Research, 39(August).

Tracy, J. L., \& Robins, R. W. (2004a). Putting the self Into self-conscious emotions: A theoretical model. Psychological Inquiry, 15(2), 103-125.

Tracy, J. L., \& Robins, R. W. (2004b). Show your pride: Evidence for a discrete emotion expression. Psychological Science, 15(3), 194-197.

Tracy, J. L., \& Robins, R. W. (2007). The psychological structure of pride: A tale of two facets. Journal of Personality and Social Psychology, 92(3), 506-525.

Van Boven, L. (2005). Experientialism, materialism, and the pursuit of happiness. Review of General Psychology, 9(2), 132-142.

Van Boven, L., \& Gilovich, T. (2003). To do or to have? That is the question. Journal of Personality and Social Psychology, 85(6), 1193-1202.

Vargo, S. L., \& Lusch, R. F. (2004). Evolving a new dominant logic for marketing. Journal of Marketing, 68(January), 1-17. 
Watson, D., Clark, L. A., \& Tellegen, A. (1988). Development and validation of brief measures of positive and negative affect: The PANAS scales Journal of Personality and Social Psychology, 54(6), 1063-1070.

Weiner, B. (1985). An attribution theory of achievement motivation and emotion. Psychological Review, 92, 548-573.

Weiner, B. (1986). An attributional theory of motivation and emotion. New York: SpringerVerlag.

Weiner, B., Russell, D., \& Lerman, D. (1979). The cognition-emotion process in achievementrelated contexts. Journal of Personality and Social Psychology, 37(7), 1211-1220.

Wernerfelt, B. (1990). Advertising content when brand choice is a signal. Journal of Business, 63(1), 91-98.

White, R. W. (1959). Motivation reconsidered: The concept of competence. Psychological Review, 66(5), 297-333. 
Table 1

Means for Experiment 1

\begin{tabular}{lcc}
\hline & Builders & Non-Builders \\
\hline WTP & $\$ 1.20(.22)$ & $\$ 0.57(.13)$ \\
Competence Scale & $4.39(.24)$ & $2.81(.22)$ \\
PANAS - Positive & $2.80(.12)$ & $2.30(.15)$ \\
PANAS - Negative & $1.19(.06)$ & $1.19(.06)$ \\
\hline
\end{tabular}

Note: Standard errors are in parentheses. 
Table 2

Moderated Mediation Analyses for Experiment 2

\begin{tabular}{lcccc}
\hline \multicolumn{1}{c}{ Predictor } & $B$ & $S E$ & $t$ & $p$ \\
\hline & Competence & & & \\
Constant & 1.76 & .23 & 7.67 & .001 \\
Build condition & 1.63 & .35 & 4.65 & .001 \\
Self-Affirmation condition & .33 & .31 & 1.08 & .28 \\
BuildXSelf-Affirmation & -1.15 & .48 & -2.42 & .02 \\
\hline & & & & .01 \\
Constant & WTP & & & .001 \\
Competence & .26 & .10 & 2.63 & .59 \\
Build condition & .12 & .03 & 3.58 & .49 \\
Self-Affirmation condition & .07 & .13 & .54 & .22 \\
BuildXSelf-Affirmation & .08 & .11 & .70 & \\
\hline & -.21 & .17 & -1.24 & .01 \\
Self-Affirmation condition & Indirect effect & $S E$ & .07 & 2.80 \\
\hline No Affirmation & .19 & .04 & 1.34 & .18 \\
Self-Affirmation & .06 & & & \\
\hline
\end{tabular}


Figure 1

Mean Willingness-to-Pay in Experiment 2

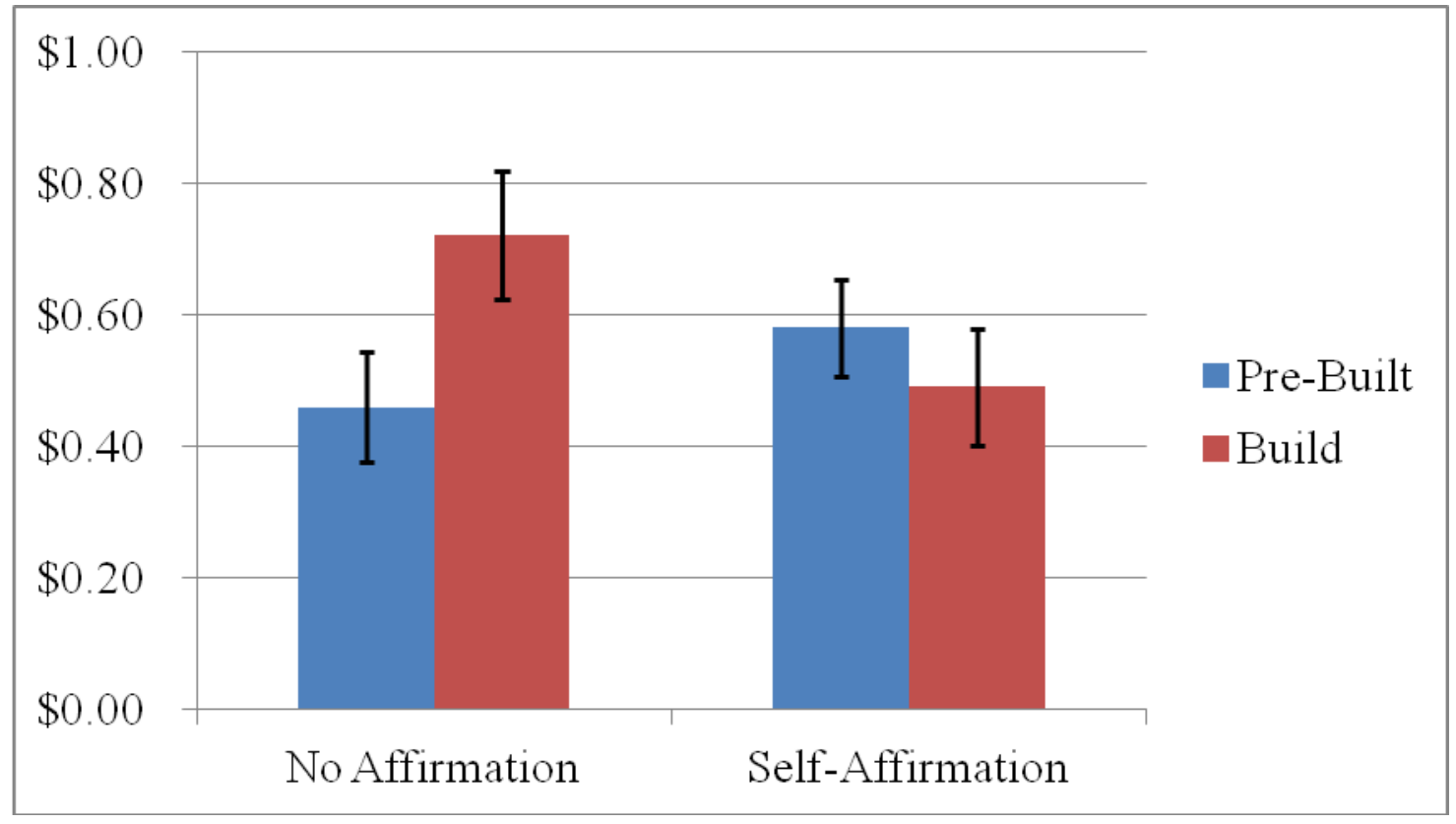

Note: Bars represent standard errors. 
Figure 2

Percent preferring to assemble their own furniture in Experiment $3 \mathrm{~A}$

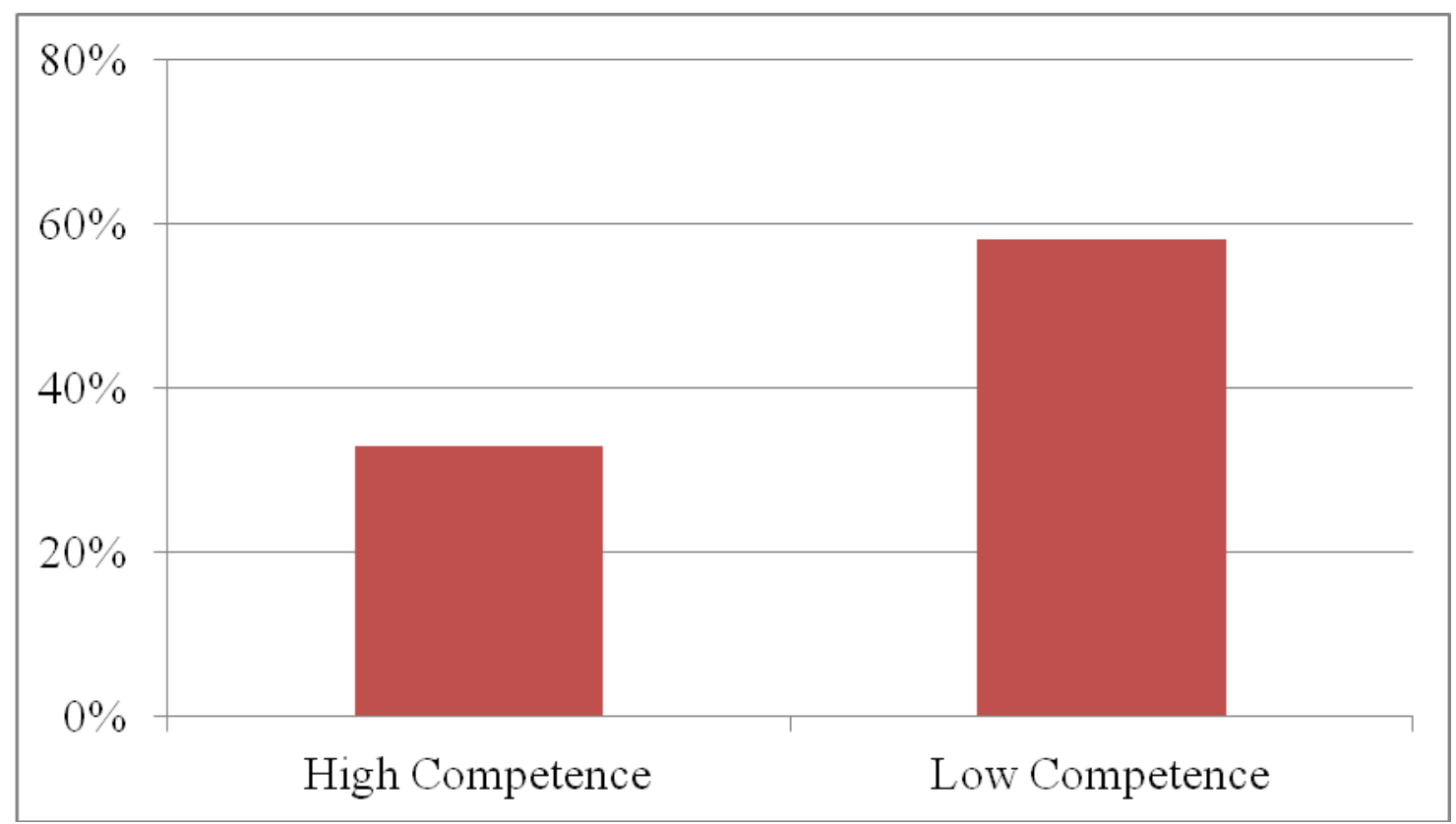

